\title{
Reversible Control of Primary and Secondary Self-Assembly of Poly(4-allyloxystyrene)-Block-Polystyrene
}

\author{
Eri Yoshida and Satoshi Kuwayama \\ Department of Materials Science, Toyohashi University of Technology, 1-1 Hibarigaoka, Tempaku-cho, \\ Toyohashi, Aichi 441-8580, Japan \\ Correspondence should be addressed to Eri Yoshida, eyoshida@tutms.tut.ac.jp
}

Received 17 February 2009; Accepted 18 May 2009

Recommended by Alaa Abd-El-Aziz

The reversible control of primary and secondary self-assemblies was attained using a poly(4-allyloxystyrene)-block-polystyrene diblock copolymer (PASt- $b$-PSt) through variations in temperature. The copolymer showed no self-assembly in cyclohexane over $35^{\circ} \mathrm{C}$ and existed as a unimer with a $37.1 \mathrm{~nm}$ hydrodynamic diameter. When the temperature was lowered to $30^{\circ} \mathrm{C}$, the copolymer formed micelles with $269.9 \mathrm{~nm}$ by the primary self-assembly. As the result of further lowering the temperature to $20^{\circ} \mathrm{C}$, the secondary self-assembly of the micelles occurred to produce ca. $2975.9 \mathrm{~nm}$ aggregates. The aggregates were dissociated into unimers by increasing the temperature up to $40^{\circ} \mathrm{C}$. The light scattering studies demonstrated that the thermoresponsivity of the copolymer showed good hysteresis throughout the variation in the temperature in the range between 20 and $40^{\circ} \mathrm{C}$, based on the Marquadt analysis of the hydrodynamic diameter distribution. It was found that the primary and secondary self-assemblies of the copolymer were perfectly controlled by the temperature.

Copyright (C) 2009 E. Yoshida and S. Kuwayama. This is an open access article distributed under the Creative Commons Attribution License, which permits unrestricted use, distribution, and reproduction in any medium, provided the original work is properly cited.

\section{Introduction}

The secondary self-assembly of molecular aggregates is important for effective control of the activity and function produced by the primary self-assembly of the molecules. The secondary aggregation spontaneously occurs through a number of attractive forces such as van der Waals interaction, solvation, depletion, bridging, $\pi-\pi$ stacking, hydrogen bond, and coordination bond [1]. The secondary selfassembly is well known as the formation of the quaternary structure of proteins with a high molecular weight over 100000 daltons. Examples for the proteins include the hemoglobin [2], microtubules [3], pyruvate dehydrogenase complexes [4], influenza virus [5], tobacco mosaic virus [6-8], tomato bushy stunt virus $[9,10]$, and aspartate transcarbamylase [11]. Thus, the secondary aggregation has widely been discovered in the natural world, while it has been explored for artificial molecules such as dilauroylphosphatidylcholine with dipalmitoylphosphatidylethanolamineconjugated biotin [12], polystyrene-block-poly(acrylic acid) [13], polystyrene-block-poly(4-vinylpyridine) onto silica nanoparticles [14], poly(isobutene)-grafted boehmite rods [15], poly(ethylenimine)-graft-poly(ethylene glycol) [16], and a metallo-supramolecular diblock copolymer consisting of polystyrene block connected to a poly(ethylene oxide) by a bis(terpyridine)ruthenium complex [17]. In addition to these experimental results, there are many theoretical results concerning the secondary aggregation $[18,19]$.

We found that the primary and secondary self-assembly of a poly(4-allyloxystyrene)-block-polystyrene diblock copolymer (PASt- $b$-PSt) was reversibly controlled by a variation in temperature. The thermoresponsivity of this block copolymer showed good hysteresis in the range between 20 and $40^{\circ} \mathrm{C}$. This study describes the reversible control of the primary and secondary self-assemblies of the PASt- $b$-PSt copolymer in cyclohexane.

\section{Experiment}

2.1. Instrumentation. The ${ }^{1} \mathrm{H}$ NMR measurements were conducted using a Varian 300 FT NMR spectrometer. Light 


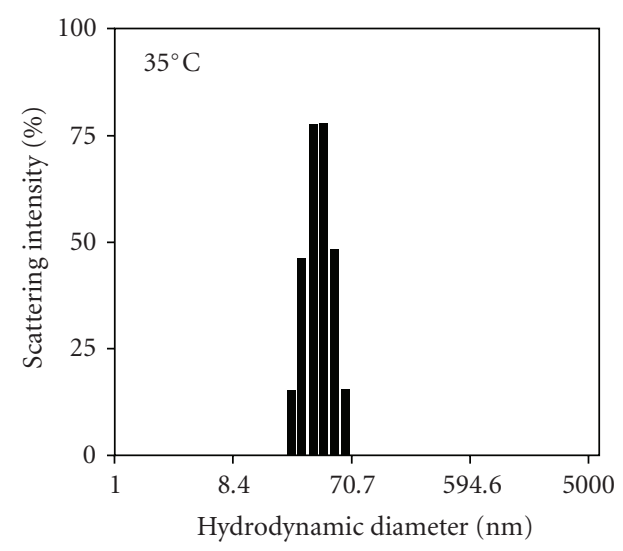

(a)

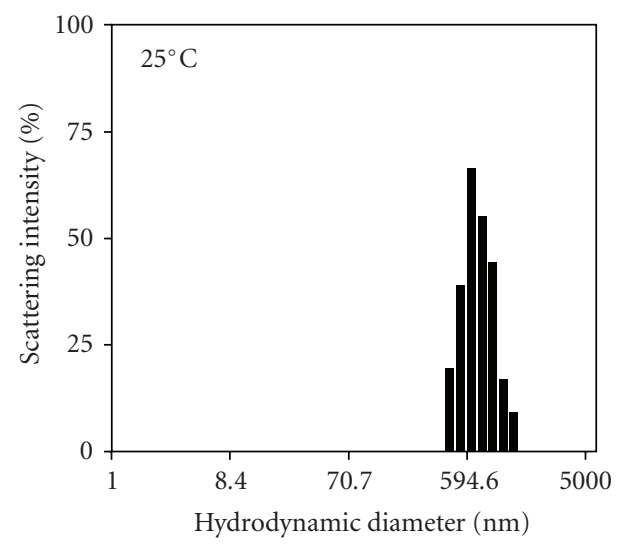

(c)

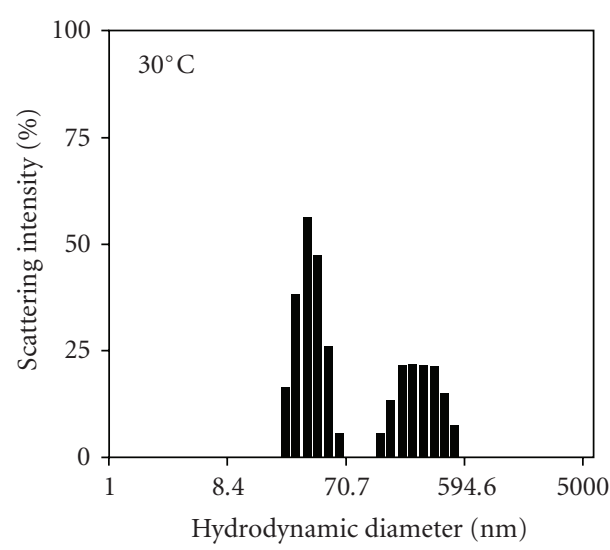

(b)

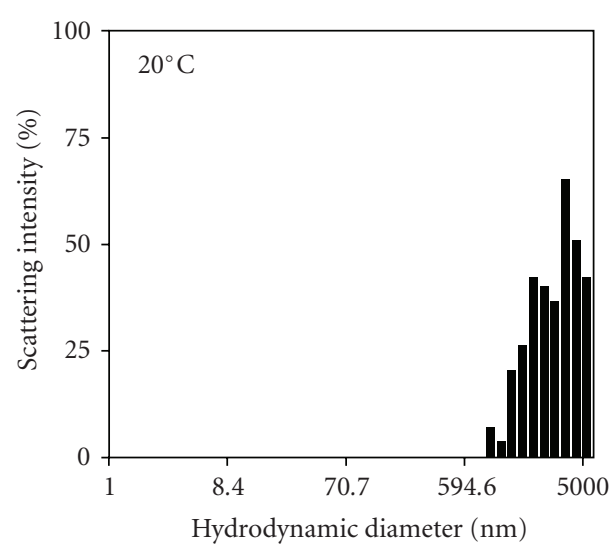

(d)

FIGURE 1: The variability in the hydrodynamic diameter distributions of the copolymer versus the temperature. $[\text { copolymer }]_{0}=1.64 \mathrm{~g} / \mathrm{L}$.

scattering measurements were performed with a Photal Otsuka Electronics ELS-8000 electrophoretic light scattering spectrophotometer equipped with a system controller, an ELS controller, and an He-Ne laser operating at $\lambda=632.8$ $\mathrm{nm}$. UV analysis was performed with a Shimadzu UV-160A UV-Vis recording spectrophotometer.

2.2. Materials. A poly(4-tert-butoxystyrene)-block-polystyrene diblock copolymer (PBSt- $b$-PSt) was prepared as reported previously [20]. The molecular weight of the copolymer was $\mathrm{Mn}(\mathrm{PBSt}-b-\mathrm{PSt})=15400-b-96600$ by ${ }^{1} \mathrm{H}$ NMR, while the molecular weight and its distribution were $\mathrm{Mn}=58000$, and $\mathrm{Mw} / \mathrm{Mn}=1.36$ by gel permeation chromatography based on polystyrene standards. Tetrahydrofuran (THF) and cyclohexane were distilled over sodium. $N, N$-Dimethylformamide (DMF) was distilled over calcium hydride under reduced pressure. Allyl chloride was also distilled over calcium hydride.

2.3. Synthesis of PASt-b-PSt. The PBSt-b-PSt $(2.00 \mathrm{~g})$ was dissolved in THF $(70 \mathrm{~mL})$. Concentrated hydrochloric acid $(7 \mathrm{~mL})$ was added to the copolymer solution. The mixture was heated at $85^{\circ} \mathrm{C}$ for 4.5 hours. The resulting solution was concentrated to ca. $30 \mathrm{~mL}$ by an evaporator, and was poured into water $(1 \mathrm{~L})$ to precipitate a polymer. The precipitates were collected by filtration, then freeze-dried with 1,4-dioxane to obtain poly(vinylphenol)-block-polystyrene diblock copolymer (PVPh- $b$-PSt, $1.593 \mathrm{~g}$ ). The PVPh- $b$-PSt $(0.70 \mathrm{~g})$ was dissolved in DMF $(15 \mathrm{~mL})$. Sodium hydride $(0.414 \mathrm{~g}, 17.3 \mathrm{mmol})$ was added to the copolymer solution at $0^{\circ} \mathrm{C}$ under nitrogen atmosphere. The suspension was stirred at $0^{\circ} \mathrm{C}$ for 5 minutes and was further stirred at room temperature for 1 hour. Allyl chloride $(1.41 \mathrm{~g}, 18.4 \mathrm{mmol})$ in DMF $(5 \mathrm{~mL})$ was added to the suspension at $0^{\circ} \mathrm{C}$. The mixture was stirred at $0^{\circ} \mathrm{C}$ for 5 minutes and was further stirred at room temperature for 20 hours. The resulting solution was poured into methanol $(1 \mathrm{~L})$ to precipitate a polymer. The precipitates were collected by filtration, then dried in vacuo for several hours. PASt- $b$-PSt $(0.68 \mathrm{~g})$ was obtained. The molecular weight of the PASt- $b$-PSt was determined to be $\mathrm{Mn}$ (PASt- $b$-PSt $)=14000-b-96600$ by ${ }^{1} \mathrm{H}$ NMR.

2.4. Light Scattering Measurements. Cyclohexane $(5 \mathrm{~mL})$ was added to PASt- $b$-PSt $(8.2 \mathrm{mg})$, and the mixture was completely dissolved at $40^{\circ} \mathrm{C}$. The solution was injected through a microporous filter into a cell using a syringe. The solution was subjected to light scattering at the angle $\theta=90^{\circ}$. 


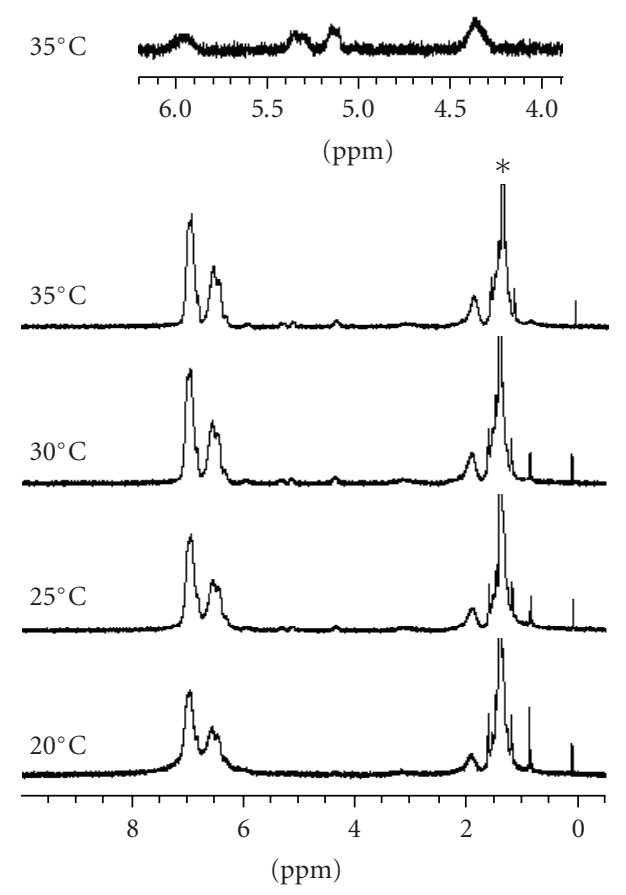

Figure 2: The variation in the ${ }^{1} \mathrm{H}$ NMR spectra of the copolymer versus the temperature. Solvent: cyclohexane- $d_{12}$. $[\text { copolymer }]_{0}=$ $1.6 \mathrm{~g} / \mathrm{L}, *$ Cyclohexane.

The hydrodynamic diameter of the copolymer was estimated by the cumulant analysis, while the scattering intensity distribution of hydrodynamic diameter was obtained by the Marquadt analysis [21].

\section{Results and Discussion}

The PASt- $b$-PSt diblock copolymer showed no self-assembly in cyclohexane at $40^{\circ} \mathrm{C}$ and existed as a unimer of an isolated copolymer. The light scattering demonstrated that the copolymer formed aggregates by decreasing the temperature. Figure 1 shows a variation in the scattering intensity distribution for the hydrodynamic diameter of the copolymer when the temperature decreased. The scattering intensity distributions were obtained by the Marquadt analysis [21]. The copolymer still existed as a unimer at $35^{\circ} \mathrm{C}$, so that only one distribution was observed around $35 \mathrm{~nm}$. When the temperature was lowered to $30^{\circ} \mathrm{C}$, another distribution was observed around $270 \mathrm{~nm}$ in addition to the unimer distribution. The distribution around $270 \mathrm{~nm}$ was attributed to the micelles formed by the primary self-assembly of the copolymer. The unimer distribution completely disappeared at $25^{\circ} \mathrm{C}$ and only distribution was observed around $700 \mathrm{~nm}$. This distribution was further shifted to the hydrodynamic diameter around $3000 \mathrm{~nm}$ at $20^{\circ} \mathrm{C}$ and did not retain the Gauss distribution any longer. The formation of the aggregates with the hydrodynamic diameter over $1000 \mathrm{~nm}$ should be caused by the secondary aggregation of the micelles. In addition, the exact hydrodynamic diameters were estimated by the Marquadt analysis to be $37.1 \mathrm{~nm}\left(35^{\circ} \mathrm{C}\right)$,

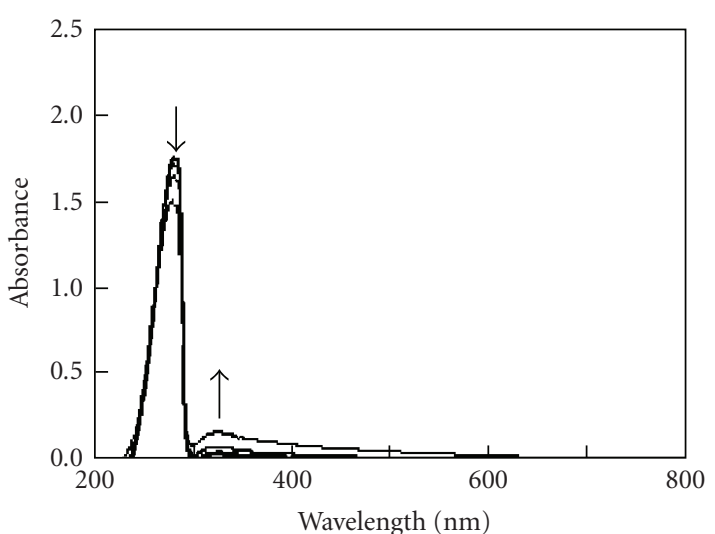

(a)

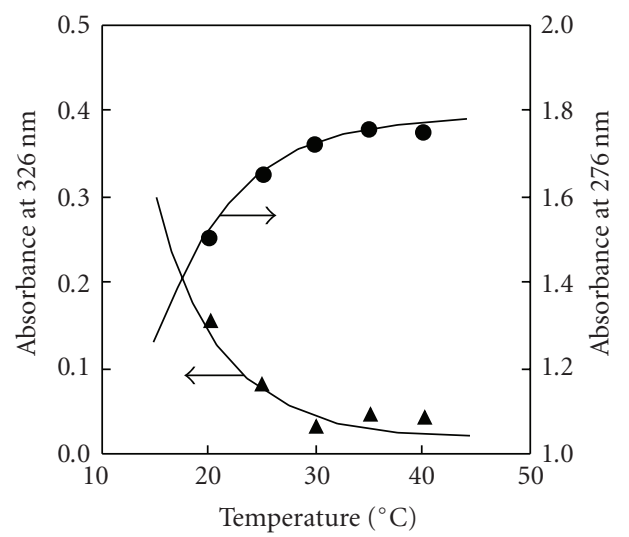

(b)

FIGURE 3: The variation in the UV spectra of the copolymer and the plots of the absorbance at $(\bullet) 276$ and $(\boldsymbol{\Lambda}) 326 \mathrm{~nm}$ versus the temperature. $[\text { copolymer }]_{0}=1.64 \mathrm{~g} / \mathrm{L}$.

$35.1 \mathrm{~nm}$ for the unimer and $269.9 \mathrm{~nm}$ for the micelles $\left(30^{\circ} \mathrm{C}\right)$, $698.0 \mathrm{~nm}\left(25^{\circ} \mathrm{C}\right)$, and $2975.9 \mathrm{~nm}\left(20^{\circ} \mathrm{C}\right)$.

The self-assembly of the copolymer was also explored by ${ }^{1} \mathrm{H}$ NMR. Figure 2 shows the ${ }^{1} \mathrm{H}$ NMR spectra obtained at each temperature using cyclohexane- $d_{12}$. In the spectrum at $35^{\circ} \mathrm{C}$, all the protons composing the copolymer were observed, since the copolymer existed as a unimer. The signals at 1.0-2.5, 4.3-4.5, 5.2-5.6, 5.8-6.1, and 6.2-7.5 ppm were assigned to the protons of the main chain, the allyl protons, the $\alpha$-proton of the vinyl, its $\beta$-protons, and the aromatic protons, respectively. The copolymer showed negligible changes at $30^{\circ} \mathrm{C}$, although part of the aromatic proton signal at $6.3 \mathrm{ppm}$ was slightly broadened. This signal was more broad at $25^{\circ} \mathrm{C}$ and was observed as a shoulder. At $20^{\circ} \mathrm{C}$, all of the signals were broadened and, in particular, the protons of the allyl groups were barely discerned. The signal broadening was based on the protons shielded by the copolymer self-assembling. The marked effect of the shielding at $20^{\circ} \mathrm{C}$ indicates that not only the cores of the micelles but also the shells were shielded by the secondary aggregation.

The degree of the shielding was determined by UV analysis. Figure 3 shows the UV spectra of the copolymer at 


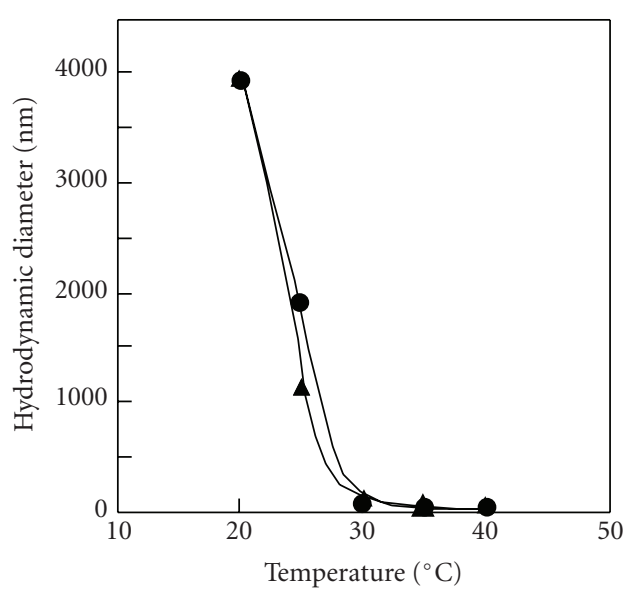

(a)

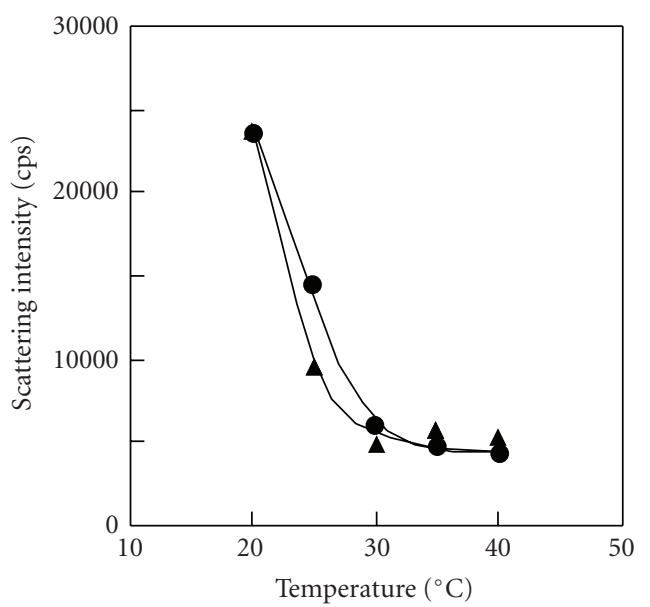

(b)

Figure 4: The variation in the hydrodynamic diameter and scattering intensity of the copolymer with $(\bullet)$ the decrease and $(\mathbf{\Delta})$ increase in the temperature. [copolymer $]_{0}=1.64 \mathrm{~g} / \mathrm{L}$.

the respective temperatures and the plots of the absorbance at 276 and $326 \mathrm{~nm}$ versus the temperature. The absorbance at $326 \mathrm{~nm}$ increased as the temperature decreased. Contrarily, the absorbance at $276 \mathrm{~nm}$ decreased with the decreased temperature. Both the decrease and increase in the absorbances were accelerated below $30^{\circ} \mathrm{C}$. The decrease in the absorbance at $276 \mathrm{~nm}$ is based on the shielding of the aromatic groups and the olefins, while the increase at $326 \mathrm{~nm}$ is attributed to an increase in the interaction among the aromatic groups and the olefins. This is accounted for by the fact that the delocalization of electrons causes red shift.

The light scattering studies revealed that the primary and secondary aggregation of the copolymer was reversibly controlled by the temperature. The thermoresponsivity of the copolymer is shown in Figure 4. The hydrodynamic diameters were estimated by the cumulant analysis. The hydrodynamic diameter and scattering intensity increased by lowering the temperature, however, those reverted to the original values as a result of raising the temperature. The aggregates were dissociated into unimers. The course of the dissociation was almost the same as that of the aggregation, indicating that the primary and secondary self-assemblies of the copolymer were perfectly controlled by the temperature.

\section{Conclusion}

The reversible control of the primary and secondary selfassemblies was attained using the PASt- $b$-PSt diblock copolymer. The copolymer formed micelles with ca. $270 \mathrm{~nm}$ hydrodynamic diameter by the primary self-assembly. The micelles were further self-assembled into large aggregates with $3000 \mathrm{~nm}$ following the formation of $700 \mathrm{~nm}$ aggregates. The aggregates formed by the secondary assembly were dissociated into unimers by increasing the temperature. It was found that the primary and secondary self-assemblies of the copolymer were perfectly controlled by the temperature based on the fact that the thermoresponsivity of the copolymer showed good hysteresis. This is the first study demonstrating that the primary and secondary self-assemblies of the diblock copolymer were reversibly controlled by the variation in the temperature in the narrow range between 20 and $40^{\circ} \mathrm{C}$.

\section{References}

[1] Y. S. Lee, Self-Assembly and Nanotechnology: A Force Balance Approach-Part 1: Self-Assembly, Wiley-Interscience, New York, NY, USA, 2008.

[2] M. F. Perutz, "Hemoglobin structure and respiratory transport," Scientific American, New Series, vol. 239, no. 6, pp. 92$125,1978$.

[3] P. Dustin, "Microtubules," Scientific American, New Series, vol. 243, no. 2, pp. 59-68, 1980.

[4] L. J. Reed, "Multienzyme complexes," Accounts of Chemical Research, vol. 7, no. 2, pp. 40-46, 1974.

[5] J. N. Varghese, W. G. Laver, and P. M. Colman, "Structure of the influenza virus glycoprotein antigen neuraminidase at 2.9 A resolution," Nature, vol. 303, no. 5912, pp. 35-40, 1983.

[6] A. C. Bloomer, J. N. Champness, G. Bricogne, R. Staden, and A. Klug, "Protein disk of tobacco mosaic virus at $2.8 \AA$ resolution showing the interactions within and between subunits," Nature, vol. 276, no. 5686, pp. 362-368, 1978.

[7] K. Namba and G. Stubbs, "Structure of tobacco mosaic virus at $3.6 \AA$ resolution: implications for assembly," Science, vol. 231, no. 4744, pp. 1401-1406, 1986.

[8] P. J. Butler and A. Klug, "The assembly of a virus," Scientific American, New Series, vol. 239, no. 5, pp. 62-69, 1978.

[9] S. C. Harrison, A. J. Olson, C. E. Schutt, and F. K. Winkler, "Tomato bushy stunt virus at $2.96 \AA$ resolution," Nature, vol. 276, no. 5686, pp. 368-373, 1978.

[10] S. C. Harrison, "Multiple modes of subunit association in the structures of simple spherical viruses," Trends in Biochemical Sciences, vol. 9, no. 8, pp. 345-351, 1984.

[11] E. R. Kantrowitz, S. C. Pastra-Landis, and W. N. Lipscomb, "E. coli aspartate transcarbamylase-part II: structure and allosteric interactions," Trends in Biochemical Sciences, vol. 5, no. 6, pp. 150-153, 1980.

[12] S. Chiruvolu, S. Walker, J. Israelachvili, F.-J. Schmitt, D. Leckband, and J. A. Zasadzinski, "Higher order self-assembly of vesicles by site-specific binding," Science, vol. 264, no. 5166, pp. 1753-1756, 1994. 
[13] L. Zhang and A. Eisenberg, "Morphogenic effect of added ions on crew-cut aggregates of polystyrene- $b$-poly(acrylic acid) block copolymers in solutions," Macromolecules, vol. 29, no. 27, pp. 8805-8815, 1996.

[14] M. Motornov, R. Sheparovych, R. Lupitskyy, E. MacWilliams, and S. Minko, "Responsive colloidal systems: reversible aggregation and fabrication of superhydrophobic surfaces," Journal of Colloid and Interface Science, vol. 310, no. 2, pp. 481-488, 2007.

[15] J. Buitenhuis, J. K. G. Dhont, and H. N. W. Lekkerkerker, "Static and dynamic light scattering by concentrated colloidal suspensions of polydisperse sterically stabilized boehmite rods," Macromolecules, vol. 27, no. 25, pp. 7267-7277, 1994.

[16] H. Wang, X. Chen, and C. Pan, "Linear poly(ethylenimine)graft-poly(ethylene glycol) copolymers: their micellization and secondary assembly," Journal of Colloid and Interface Science, vol. 320, no. 1, pp. 62-69, 2008.

[17] O. Regev, J.-F. Gohy, B. G. G. Lohmeijer, et al., "Dynamic light scattering and cryogenic transmission electron microscopy investigations on metallo-supramolecular aqueous micelles: evidence of secondary aggregation," Colloid and Polymer Science, vol. 282, no. 4, pp. 407-411, 2004.

[18] P. van der Schoot, "Remarks on the association of rodlike macromolecules in dilute solution," Journal of Physical Chemistry, vol. 96, no. 14, pp. 6083-6086, 1992.

[19] J. Groenewold and W. K. Kegel, "Anomalously large equilibrium clusters of colloids," Journal of Physical Chemistry B, vol. 105, no. 47, pp. 11702-11709, 2001.

[20] E. Yoshida and S. Kuwayama, "Micelle formation induced by photolysis of a poly(tert-butoxystyrene)-block-polystyrene diblock copolymer," Colloid and Polymer Science, vol. 285, no. 11, pp. 1287-1291, 2007.

[21] D. W. Marquardt, "An algorithm for least-squares estimation of nonlinear parameters," SIAM Journal on Applied Mathematics, vol. 11, no. 2, pp. 431-441, 1963. 


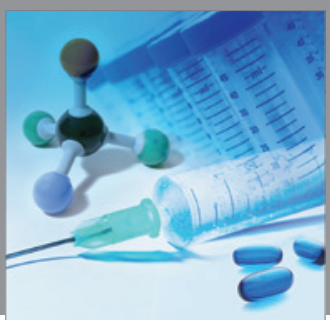

International Journal of

Medicinal Chemistry

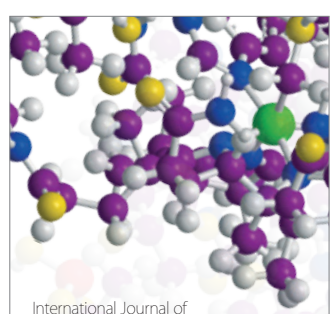

Carbohydrate Chemistry

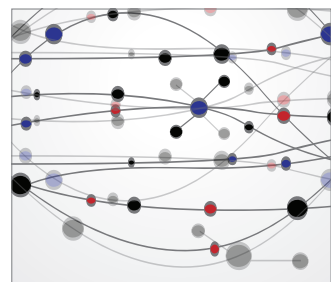

The Scientific World Journal
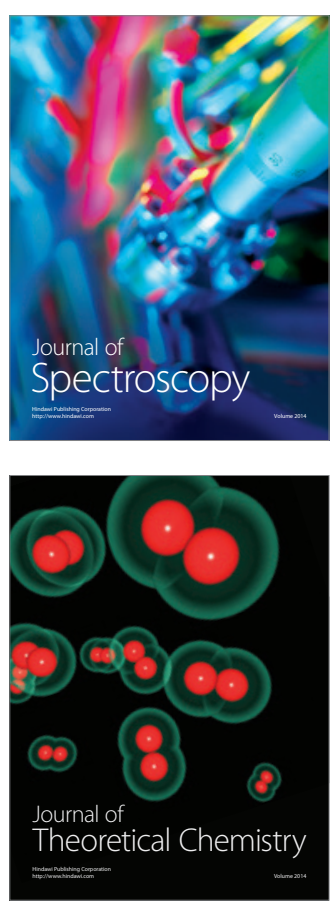
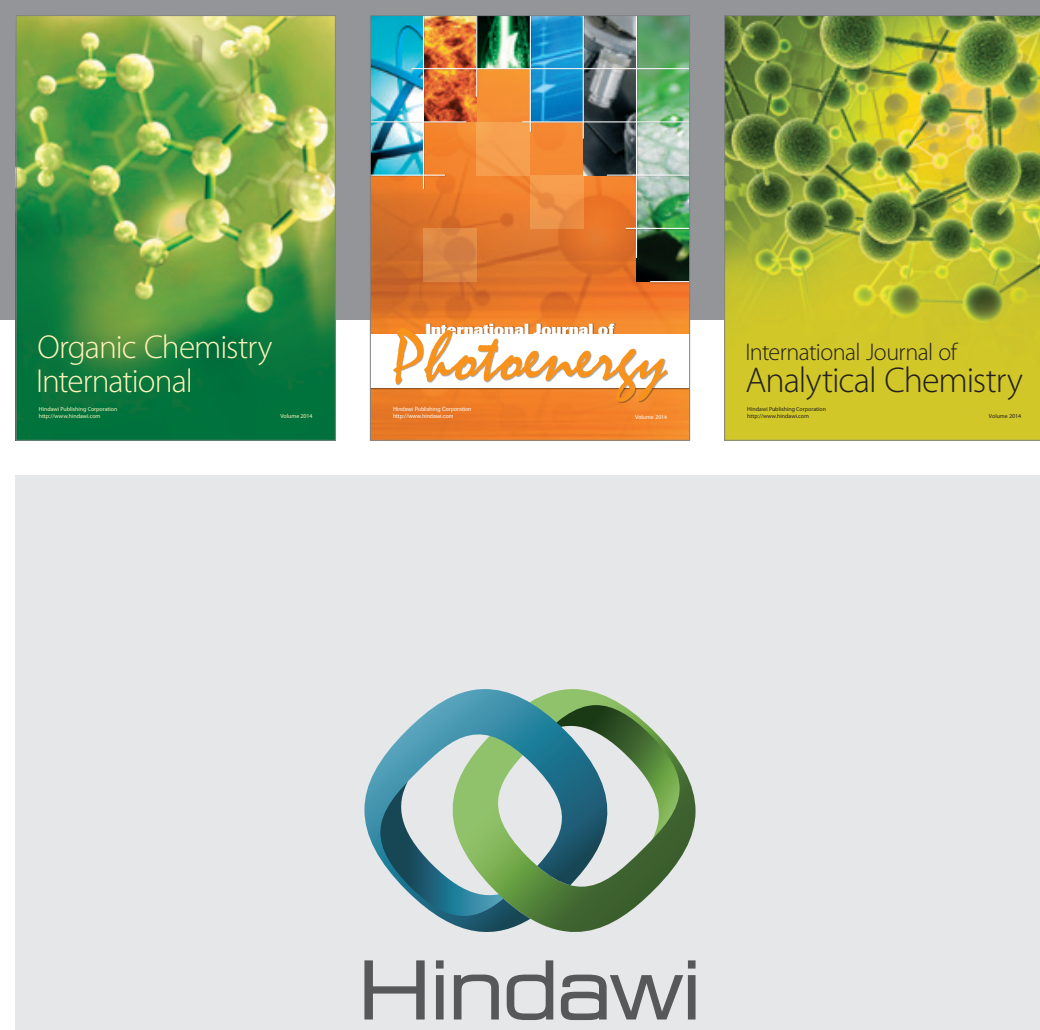

Submit your manuscripts at

http://www.hindawi.com
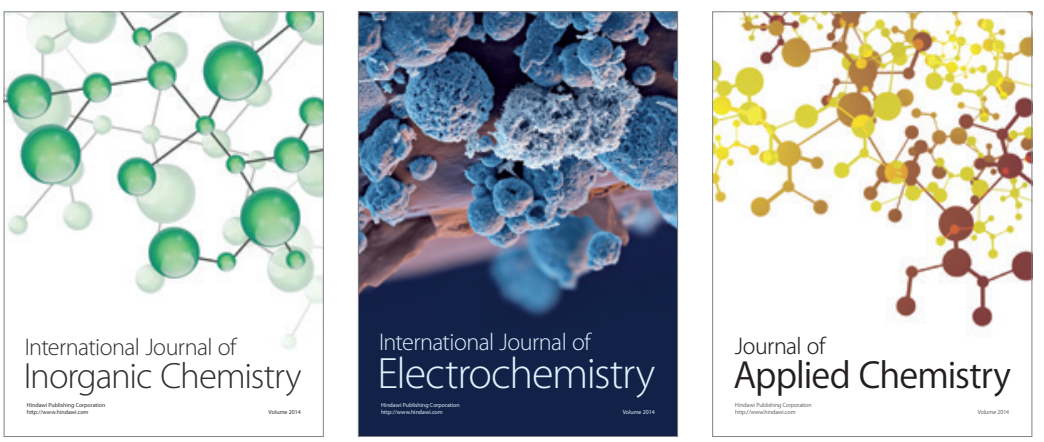

Journal of

Applied Chemistry
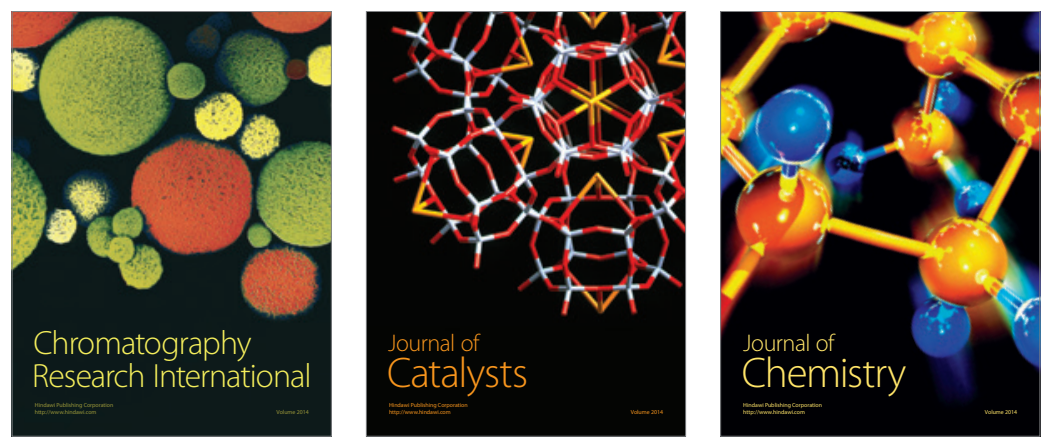
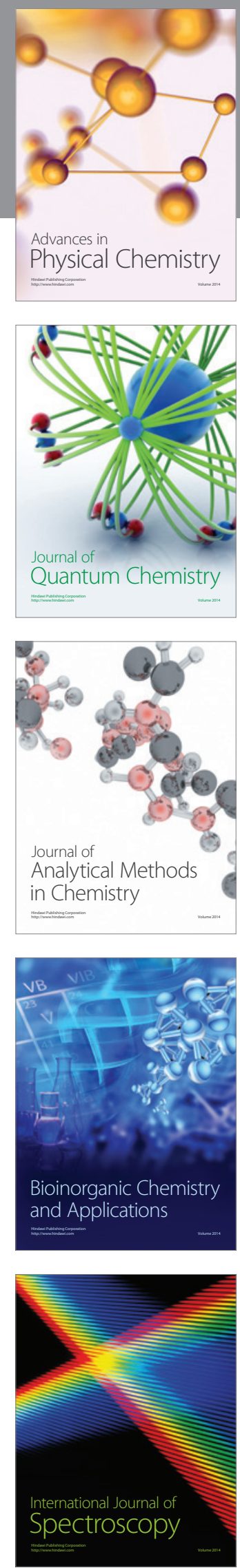